Had a stormy post- operative course with two incidents of peri-arrest due to blocked tracheostomy. These two incidents caused significant anxiety and distress for the child, for which he received psychology input. Decannulation done day 5 postop, discharged home on post-op day 10, with a course oral antibiotics.

Conclusions The present case describes a typical but severe case of Ludwig's angina in a relatively atypical age group. This is a life -threatening condition, which requires early intervention along with a multidisciplinary team input. While relatively uncommon in the paediatric population, clinicians should be aware and understand the urgency of immediate treatment when it does present.

\section{BONE PROFILE IN LOW BIRTH WEIGHT BABIES: WHAT WE LEARN}

Hnin Pwint Oo, Nyan Sin Htun, Nay Aung, Nilar Lwin. Myanmar

\subsection{6/bmjpo-2021-RCPCH.106}

Background Bone profile in low birth weight (LBW) babies is important for monitoring of metabolic bone disease(MBD). $\mathrm{MBD}$ is a clinically heterogeneous group of disease with commonly reversible clinical presentation and manifestation when the underlying defect has been treated.

Objectives This study was aimed to find out biochemical profile in LBW babies and association between bone profile and gestational age of LBW.

Methods A cross-sectional descriptive study was done in all LBW infants at 8 weeks of age within one year period. Infants with less than 28 weeks of gestation, infants with insufficient perinatal records and those with suspicion of renal, hepatic, gastrointestinal and thyroid diseases were excluded.

Results Total 60 LBW (45 preterm and 15 small for gestational age, SGA) babies were included. Biochemical parameters of bone profile were shown in table 1 . Sixteen babies $(26.7 \%)$ were found MBD, comprising $68.7 \%$ of preterm and $31.3 \%$ of SGA infants. The mean serum calcium level was not statistically significant (table2) whereas mean serum phosphate and alkaline phosphatase levels were significantly different between low birth weight infants with MBD and those without MBD (table $3 \& 4$ ).

Abstract 196 Table 1 Biochemical parameters of LBW

\begin{tabular}{lllll}
\hline Variables & Mean & Standard deviation & Minimum & Maximum \\
\hline Calcium(mg/dl) & 7.12 & 0.524 & 8.28 & 10.96 \\
Phosphate(mg/dl) & 2.41 & 0.722 & 1.85 & 11.64 \\
Alkaline phosphatase(IU/L) & 400 & 16 & 100 & 700 \\
\hline
\end{tabular}

Abstract 196 Table 2 Association between serum calcium and gestational age of LBW

\begin{tabular}{|c|c|c|c|c|c|c|c|}
\hline \multirow[t]{2}{*}{ Calcium } & \multicolumn{4}{|c|}{ Gestational age(week) } & \multirow{2}{*}{$\begin{array}{l}\text { Total } \\
-(\%)\end{array}$} & \multirow{2}{*}{$\begin{array}{l}\text { Chi- } \\
\text { square }\end{array}$} & \multirow{2}{*}{$\begin{array}{l}\mathrm{p} \text { - } \\
\text { value }\end{array}$} \\
\hline & $28-31(\%)$ & $31-34(\%)$ & $34-37(\%)$ & $37-40(\%)$ & & & \\
\hline Low & 25 & 31.25 & 31.25 & 12.5 & 100 & 3.63 & 0.727 \\
\hline Normal & 12.2 & 26.82 & 36.58 & 24.4 & 100 & & \\
\hline High & 33.3 & 0 & 33.3 & 33.4 & 100 & & \\
\hline
\end{tabular}

Abstract 196 Table 3 Association between serum phosphate and gestational age of LBW

\begin{tabular}{|c|c|c|c|c|c|c|c|}
\hline \multirow[t]{2}{*}{ Phosphate } & \multicolumn{4}{|c|}{ Gestational age(week) } & \multirow{2}{*}{$\begin{array}{l}\text { Total } \\
-(\%)\end{array}$} & \multirow{2}{*}{$\begin{array}{l}\text { Chi- } \\
\text { square }\end{array}$} & \multirow{2}{*}{$\begin{array}{l}\mathrm{p} \text { - } \\
\text { value }\end{array}$} \\
\hline & $28-31(\%)$ & $31-34(\%)$ & $34-37(\%)$ & $37-40(\%)$ & & & \\
\hline Low & 50 & 12.5 & 12.5 & 25 & 100 & 35.828 & 0.000 \\
\hline Normal & 27.77 & 0 & 72.23 & 0 & 100 & & \\
\hline High & 2.9 & 44.11 & 20.59 & 32.4 & 100 & & \\
\hline
\end{tabular}

Abstract 196 Table 4 Association between serum alkaline phosphatase and gestational age of LBW

\begin{tabular}{llllllll}
\hline Alkaline & \multicolumn{2}{l}{ Gestational age(week) } & & Total & Chi- & p- \\
phosphatase & \multicolumn{2}{l}{ square } & value \\
\cline { 2 - 7 } & $28-31(\%)$ & $31-34(\%)$ & $34-37(\%)$ & $37-40(\%)$ & & & \\
\hline Low & 0 & 0 & 0 & 0 & 0 & 13.918 & 0.003 \\
Normal & 0 & 0 & 88.89 & 11.11 & 100 & & \\
High & 19.6 & 31.37 & 25.5 & 23.53 & 100 & & \\
\hline
\end{tabular}

Conclusions MBD is more common in preterm babies than SGA babies. Serum calcium does not correlate well with gestational age of low birth weight infants where as serum phosphate and alkaline phosphatase have significant correlation. Diagnosis of $\mathrm{MBD}$ can be suspected on the abnormality of biochemical data, especially serum phosphate and alkaline phosphatase levels. Thus, measurement of biochemical bone profile has been recommended for early detection of MBD in high risk infants.

\section{SPECTRUM OF SYMPTOMS IN COVID-19 PAEDIATRIC PATIENTS ACROSS FOUR DISTRICT GENERAL HOSPITALS IN YORKSHIRE}

Sharon Chan, Rajeeva Singh, Alexander-John Shuttleworth. UK

\subsection{6/bmjpo-2021-RCPCH.107}

Background Despite increasing reports and studies about COVID-19 in children over the last nine months, there is still much to be discovered about the true incidence, clinical presentations and transmission rates in children. Fever and respiratory symptoms remain the main clinical presentations in COVID-19 positive children. Symptoms of COVID-19 in the paediatric population appear to be less severe compared to those experienced in the adult population and there is a low case fatality rate for COVID-19 in children. More recently there have been increasing reports of children with Paediatric multisystem inflammatory syndrome temporally associated with COVID-19 (PIMS).

Objectives The objectives of this study were to evaluate the spectrum of clinical presentations and evolution of clinical symptoms, management and outcomes of children with laboratory confirmed COVID-19 who presented to secondary care to help guide future management of these patients. We also describe two cases of Paediatric multisystem inflammatory syndrome temporally associated with COVID-19 (PIMS).

Methods Our study is a retrospective observational study which identified 21 patients aged 1 month to 18 years with positive COVID-19 PCR and 2 patients with PIMS over a 10 